\title{
Contextualizando a educação rural espanhola nos séculos XX e XXI
}

\author{
Contextualizing education in rural Spanish $20^{\text {th }}$ and $21^{\text {st }}$ centuries
}

\author{
Contextualizando la educación rural española en los siglos XX y XXI
}

Flávio Reis dos Santos ${ }^{2}$

\begin{abstract}
Resumo: Este escrito que tem por objeto de estudo o meio e a educação oferecida para as populações rurais espanholas e como objetivo a proposição de definições possíveis, que possam expressar o entendimento sobre a educação rural concebida historicamente a partir das transformações econômicas capitalistas entre os séculos XX e XXI. As análises buscaram reconhecer as realidades e necessidades educacionais das populações rurais, bem como apontar os meios urbano e rural como espaços que compõem o mesmo universo. No desenvolvimento da investigação focalizamos as discussões nas mudanças ocorridas com a escola e a educação rurais na Espanha, mediante análise, interpretação e reflexão de pesquisas realizadas por estudiosos espanhóis e brasileiros com o objetivo de harmonizar concepções de educação rural na sociedade contemporânea. Procuramos não restringir a nossa compreensão sobre a educação rural a uma concepção pedagógica de mera permanência do homem na terra, considerando que é preciso exteriorizar a defesa de uma formação escolar ampla e universalizante para os rurícolas a partir da questão econômica.
\end{abstract}

Palavras-chave: Educação rural. Escola rural. Espanha.

Abstract: This paper has aims for study of the environment and education offered to the Spanish rural populations and the objective of proposing possible definitions that can express the understanding about the rural education conceived historically from the capitalist economic transformations between the twentieth and twentieth-first. The analyzes sought to recognize the realities and educational needs of rural populations, as well as pointing out the urban and rural environments as spaces that make up the same universe. In the development of the research we focus the discussions on the changes that occurred with the rural school and the rural education in Spain, through analysis, interpretation and reflection of research carried out by the spanish and brazilian scholars with the objective of harmonizing conceptions of rural education in the contemporary society. We seek not to restrict our understanding of rural education to a pedagogical conception of mere permanence of man on earth, considering that it is necessary to outsource the defense of a broad and universalizing schooling to the farmers from the economic question.

Keywords: Rural education. Rural school. Spain.

Resumen: Este escrito tiene como objeto de estudio el medio y la educación ofrecidos a las poblaciones rurales españolas y su objetivo es la propuesta de posibles definiciones que puedan expresar la comprensión de la educación rural concebida históricamente a partir de las transformaciones económicas capitalistas entre los siglos XX y XXI. Las análisis buscaron reconocer las realidades y necesidades educativas de las poblaciones rurales, así como señalar los entornos urbanos y rurales como espacios que conforman el mismo universo. En el desarrollo de la investigación enfocamos las discusiones sobre los cambios que ocurrieron con la escuela y la educación rurales en España, a través del análisis, interpretación y reflexión de la investigación realizada por académicos españoles y brasileños con el objetivo de armonizar las concepciones de la educación rural en la sociedad contemporánea. Buscamos no restringir nuestra comprensión de la educación rural a una concepción pedagógica de la mera permanencia del hombre en la tierra, considerando que es necesario externalizar la defensa de una escolarización amplia y universalizadora para los agricultores de la cuestión económica.

Palabras clave: Educación rural. Escuela rural. España.

\footnotetext{
${ }^{1}$ Submetido em: 20 ago. 2019 - Aceito em: 01 out. 2019 - Publicado em: 03 set. 2020

${ }^{2}$ Universidade Estadual de Goiás (UEG) - E-mail: reisdossantos.flavio@ gmail.com
} 


\section{Introdução}

Considerando a diversidade das atividades produtivas desenvolvidas em distintos espaços territoriais e a necessidade de formação escolar, analisamos algumas particularidades históricas para apontar aspectos que podem contribuir para a especificação da educação para as populações que habitam o meio rural na Espanha. Aclaramos que a constatação, demarcação e valorização do meio, dos costumes, das tradições e das culturas rurais variam de continente para continente, de país para país, de região para região em decorrência das formas de ocupação dos territórios, dos processos de desenvolvimento históricos das concepções de mundo e de existência.

Todavia, é possível afirmar que a definição de meio rural esteve vinculada a um espaço determinado ocupado por uma pequena aglomeração de pessoas e residências, no qual predominam as paisagens naturais, que estende as suas considerações ao explicar que entre os meios urbanos e rurais se entrepõem descontinuidades que fazem do rural um espaço marcado pela fraca densidade demográfica, menor participação do trabalho assalariado no conjunto das atividades produtivas das pequenas propriedades, contrapostas à atual predominância da maquinização e tecnologização do processo produtivo nas grandes propriedades, voltado para o mercado externo (WANDERLEY, 2000).

As transformações que reordenaram a sociedade capitalista na transposição do século XX para o século XXI aprofundaram o fenômeno da globalização, que pulverizou toda e qualquer barreira impeditiva do impetuoso expansionismo capitalista, produzindo por efeito um processo de "aculturação" das populações tradicionais em todo o mundo. As particularidades que distinguiam as culturas rurais estão paulatinamente cedendo lugar a um modelo hegemônico urbanocêntrico nutrido pelas próprias necessidades e incertezas da ruralidade subjugada pela urbanidade.

A homogeneização de padrões de vida cada vez mais semelhantes aliados a estereótipos que transitam do universo urbano para o rural nos fazem contemplar de forma gradativa o não reconhecimento, ou mesmo, a indefinição de hábitos e costumes outrora vinculados ao universo rural. Nessa intensa transformação, focalizamos a educação para as pessoas que vivem no meio rural espanhol e as implicações concebidas para a construção/manutenção das comunidades rurais que representam elementos que a escola pode observar, analisar e refletir ante às dificuldades e impossibilidades de vislumbrar as vantagens e desvantagens das mudanças provocadas pelo capitalismo para as populações rurais (JIMÉNEZ, 2009).

As nossas sondagens iniciais indicaram que as pesquisas desenvolvidas sobre a educação rural na Espanha, nas últimas décadas, têm concentrado as suas análises na escola rural, associadas às questões mais amplas concernentes à própria educação para as populações rurais, consideradas a partir dos elementos que constituem a estrutura de serviços disponibilizados, dos recursos humanos, físicos, materiais e das principais necessidades locais. Buscamos no processo de investigação focalizar as discussões nas mudanças ocorridas com a escola rural na Espanha por meio da leitura, análise, interpretação e reflexão de 
estudos realizados por pesquisadores espanhóis e brasileiros com o objetivo de harmonizar conceitos de educação rural na sociedade contemporânea.

Entendemos que para além dos limites dos aspectos técnicos, ainda são relativamente incipientes as considerações sobre os aspectos históricos das relações entre os universos urbano e rural; explicitamos a importância de se ponderar sobre as relações de classe, sobre os contextos históricos que envolveram e resguardaram na sociedade capitalista a exploração imposta pelo dominante ao dominado, a salvaguarda do novo em detrimento do antigo, a valorização e predominância do urbano sobre o rural (BEZERRA NETO; SANTOS, 2016).

\section{Limites e potencialidades da educação rural na Espanha}

O modelo de escolarização utilizado na Espanha até os anos de 1970 foi caracterizado pela denominada "escola unitária", no qual os alunos eram agrupados em três categorias distintas (básica, média e superior), classificados por meio da consideração de seus conhecimentos de leitura, escrita e cálculo sob a responsabilidade e orientação de um único professor. Estamos nos referindo à ensinagem em que apenas um professor (polivalente) se desdobra para dar aulas a grupos diferentes de alunos, de diferentes níveis de aprendizagem e em situações nas quais tem que multiplicar os seus esforços para desempenhar a atividade docente com vistas a alcançar resultados positivos (HINOJO; RASO; HINOJO, 2010).

Este modelo nos é bastante familiar, visto que foi e é bastante praticado nas mais variadas localidades rurais brasileiras; modelo que conhecemos por "classe multisseriada" ou "escola multisseriada" e que bem discernimos sobre as suas realidades, necessidades e carências (MOURA; SANTOS, 2012; LOPES; BEZERRA NETO, 2013; JANATA; ANHAIA, 2015; HAGE; REIS, 2018). Os professores das classes multisseriadas, além da responsabilidade pela escolarização de crianças e adolescentes de diferentes idades classificados em distintos níveis de aprendizagem - diferentes séries - acabam, pela necessidade e falta de recursos das mais diversas ordens, assumindo inúmeras funções que se afastam totalmente das atividades docentes, como faxineiro, merendeiro, zelador, porteiro etc., situação que evidencia a sobrecarga, a desvalorização e precarização do trabalho do docente (FAGUNDES; MARTINI, 2003).

Luna (2010) esclarece que na Espanha existiam escolas unitárias para meninos, para meninas e, sobretudo, turmas mistas quando da ocorrência de número reduzido de meninos ou de meninas para a composição das turmas. Em termos gerais, o modelo básico para a escolarização das populações do meio rural - fazendas, aldeias, pequenos povoados - foi a "escola unitária mista", que não necessariamente abrigava as diferentes turmas/classes de uma determinada localidade ou região num mesmo prédio/edificação física.

Feu Gelis (2004, p. 2), de sua parte, infere que as escolas rurais funcionavam em espaços inimagináveis, em precárias condições e sem recursos econômicos, materiais e humanos no interior do território espanhol, a saber: "no pátio de uma igreja, no porão de uma repartição pública, na sala de uma casa abandonada e no pior dos casos num espaço qualquer 
convertido em 'sala de aula', que apesar de todos os esforços permaneceu inadequado para a instrução".

As transformações nas condições de existência das escolas rurais na Espanha ocorreram simultaneamente à transição da ditadura do general Francisco Franco Bahamonde (1936-1975) para a monarquia parlamentarista de Juan Carlos I (1975-2014). Luna (2010) explica que a tentativa do governo espanhol de transformar a realidade das escolas rurais e, portanto, da educação para as populações rurais, com a instituição da Lei Geral de Educação e Financiamento da Reforma Educativa n. 14 (ESPAÑA, 1970) ${ }^{\mathrm{i}}$, em realidade, deu início a um processo de fechamento das escolas rurais. Fato reiterado por Sánchez (1983), ao apontar as intenções governamentais espanholas de extinguir as escolas rurais das fazendas, aldeias e pequenos povoados:

As concentrações escolares ${ }^{\mathrm{ii}}$ têm seu precedente nos agrupamentos escolares, no começo dos anos 1960, mas é a partir da Lei Geral de Educação [1970] e mais concretamente com as Ordens Ministeriais para a Transformação e Classificação dos Centros de 1971 (30-XII) e 1972 (14-I) que se efetiva a febre da criação de centros regionais de educação e consequentemente o fechamento das escolas unitárias mistas (SÁNCHEZ, 1983, p. 29).

O processo de concentração escolar trouxe consigo significativo crescimento do transporte escolar, das despesas com alimentação dos estudantes, da construção de escolas, gerando um gasto público em educação na ordem de $16,5 \%$ no ano de 1972. O gradativo aumento com os investimentos em educação contraposto ao encerramento das escolas unitárias rurais, de acordo com as análises de Luna (2010), pode levar ao equívoco de que a qualidade da educação rural espanhola aumentou substancialmente, mas isso não aconteceu, pois:

[...] tanto a qualidade da educação como a qualidade de vida no meio rural não melhoraram, pelo contrário, o nível baixou muito, visto que o modelo de qualidade empregado era o urbano-industrial, não aplicável a muitas áreas rurais espanholas, onde não existiam distritos administrativos públicos próximos e nem facilidades para comunicação (LUNA, 2010, p. 2).

As medidas políticas empreendidas pelo governo espanhol expressaram a discriminação caracterizada pela contradição entre a valorização da cidade e o desapego às questões do meio rural, pois ressaltavam a satisfação das necessidades das áreas urbanas quanto à infraestrutura, urbanização, industrialização, serviços e equipamentos. "A transferência dessa contradição para o campo educacional evidencia a prioridade do Estado dada aos centros urbanos contra a oferta e manutenção de serviços mínimos para as pequenas populações rurais" (LUNA, 2010, p. 4). Heredero, González e Nozu (2014, p. 145) reafirmam as condições de existência da escola rural na Espanha do século XX ao apontar que esta instituição por sua localização em áreas de difícil acesso, de baixos níveis econômicos, sociais e culturais "tinha uma concepção de inferioridade em relação à escola urbana".

Analisando a realidade brasileira, chegamos a conclusões semelhantes às destacadas por Luna (2010) e por Heredero, González e Nozu (2014), visto que "o meio rural foi (é) sistematicamente associado a uma concepção determinista e discriminatória de atraso e retrocesso, ao mesmo tempo em que a cidade exprime a égide do desenvolvimentismo e da 
modernidade econômica na sociedade capitalista" (SANTOS; BEZERRA NETO, 2015, p. 179). Na mesma direção, Leite (2002, p. 14) ao analisar a educação rural no Brasil argumenta que:

[...] por motivos socioculturais [a educação rural], sempre foi relegada a planos inferiores, e teve por retaguarda ideológica o elitismo acentuado do processo educacional aqui instalado pelos jesuítas e a interpretação político-ideológica da oligarquia agrária conhecida popularmente na expressão: gente da roça não carece de estudos. Isso é coisa de gente da cidade.

Feu Gelis (2004, p. 2) reforça tal contexto ao afirmar que a escola rural na Espanha recebeu pouca atenção do Estado, que a classificava como escola de quarta categoria, escola de aldeia, escola de povoado. Tais denominações utilizadas de forma depreciativa, não teriam muita importância se não decorressem diretamente do "disparate comparativo de que as escolas rurais são inferiores às escolas urbanas, dispõem de recursos menores, seus currículos são reduzidos, não ofertam todos os níveis de ensino e o mais importante encontram-se no rol das necessidades educacionais do país".

Hernández Díaz (2000), por sua vez, ressalta que os ideais de vida, de sociedade, de valores difundidos pelos manuais e conteúdos escolares para as crianças do meio rural eram (são) predominantemente aqueles praticados e característicos no e do meio urbano. Essa concepção é indiscutivelmente evidenciada a partir de fins da década de 1960, momento em que o governo espanhol colocou em marcha o plano acelerado de esvaziamento do meio rural, sobretudo, da escola rural - conforme apontamento anterior. Hernández Díaz (2000, p. 125) argumenta "que a escola, por meio dos livros escolares convidava as crianças para a aventura da cidade, contraposta ao abandono do rural em toda a sua extensão, tendo em vista uma sociedade mais aberta e dinâmica para representar o fechamento das escolas rurais".

Chamamos a atenção do leitor para o contexto econômico mundial no qual se instalava a reordenação do sistema capitalista, que resultou na desmontagem do Estado de Bem-Estar Socialiii e no restabelecimento dos fundamentos liberais clássicos de não intervenção do Estado nas relações do mercado, livre e total concorrência, inviolabilidade da propriedade privada dos meios de produção, maximização da exploração da força de trabalho, da produtividade e dos lucros, interferindo diretamente nas políticas nacionais em todas as partes do mundo, exigindo o seu ajustamento à nova ordem econômica.

Inevitavelmente, o sistema educacional espanhol demandou mudanças em âmbito geral, a escola primária e a escola rural precisaram de ajustes e reorganização em sua estrutura, tendo em vista adequar-se às novas exigências do sistema capitalista emanadas do Banco Mundial (BM), Organização das Nações Unidas para a Educação, da Ciência e a Cultura (UNESCO), Organização para a Cooperação e Desenvolvimento Econômico (OCDE). Em busca do atendimento às pressões externas, o governo espanhol publicou em 1969 o Livro Branco sobre Educação e, em 1970, a Lei Geral de Educação (LGE). Hernández Díaz (2000) comenta, que mesmo antes das pressões dos organismos multilaterais internacionais, o staff tecnocrático do governo espanhol:

[...] já defendia um discurso que via como irremediável (mas com passividade) sobre o que estava acontecendo no mundo rural e em suas escolas. Inclusive, era a 
favor do desmantelamento do modelo de sociedade e de escola rural [unitária mista] e de outros modelos semelhantes às Concentrações Escolares e às Escolas Domésticas. O tecnocratismo se impôs fácil e estritamente por meio do campo econômico, sem atender à dimensão social e cultural que representa a escola no meio rural, sem considerar outras saídas e variáveis sobre e para o assunto, sem saber distinguir porque, de fato, não estava interessado numa escola unitária de qualidade, numa escola para a formação dos rurícolas (HERNÁNDEZ DÍAZ, 2000, p. 129).

A Lei Geral de Educação de 1970 descaracterizou centenas e centenas de escolas rurais espanholas ao definir critérios técnicos para promover a sua supressão, o seu encerramento, a sua extinção mediante a implementação das concentrações escolares. A escola unitária rural atualmente é considerada no sistema educacional espanhol residual, praticamente extinta, mesmo com o esforço depreendido pelo Programa de Educação Compensatória de 1983 (ESPAÑA, 1983). A tecnocracia estatal espanhola bem se ocupou do desmantelamento das escolas que supostamente apresentavam baixas demandas, transferindo as crianças para as escolas da cidade, sem avaliar qualquer consequência, quer positiva ou negativa social e econômica, tanto para as comunidades rurais quanto para os possíveis efeitos pedagógicos favoráveis ou não ao processo de formação escolar (HERNÁNDEZ DÍAZ, 2000; LUNA, 2010).

Somente em 1986 as populações rurais foram levadas em consideração pelo governo espanhol, decorrência direta de reivindicações e pressões iniciais de grupos vinculados à educação em Ávila ${ }^{\text {iv }}$, que propuseram formas inovadoras de resistir e lutar com o desaparecimento da escola como único referencial cultural das comunidades rurais, resultando na publicação do Decreto Real n. 2.731, de 24 de dezembro de 1986 (ESPAÑA, 1986), que estabeleceu a criação dos Colégios Rurais Agrupados de Educação Geral Básica (CRAs).

Os Colégios Rurais Agrupados fizeram frente ao fechamento das escolas no meio rural e à respectiva transferência de seus alunos para as escolas da cidade, exprimindo uma perspectiva inovadora de escola e de educação para e nas fazendas, aldeias e pequenos povoados. Entretanto, alguns aspectos que caracterizaram as condições de existência e funcionamento das escolas unitárias rurais foram replicados como a falta de recursos econômico-financeiros para a manutenção das unidades, deficiências físicas, materiais e humanas, sobretudo, aquelas relacionadas à formação dos professores.

De qualquer modo, os CRAs representam a permanência da escola para a formação educacional das populações que habitam no meio rural, bem como uma educação que tem como pilares de sustentação o território e a cultura rural e conta com:

[...] uma estrutura didático-pedagógica baseada na heterogeneidade e multinivelaridade de grupos de distintas idades, capacidades, competências curriculares e níveis de escolarização, e, com uma estrutura organizacional e administrativa singular, adaptada às características e necessidade inerentes ao contexto em que se encontra inserida (TOMÁS, 2004, p. 13).

O modelo educacional praticado nas escolas rurais espanholas se caracterizou por sua organização particularizada e específica, com vistas a adequar-se "à singularidade e idiossincrasia do meio para garantir uma educação de qualidade respeitando a identidade de 
cada um"; ocorrência que nos permite "apreciar diferentes estruturas organizacionais como, por exemplo, colégios rurais agrupados, centros incompletos e escolas unitárias” (RUIZ; GIL, 2011, p. 142). Certamente, que a quantidade de alunos constitui fator fundamental na "organização da instituição quanto à manutenção de sua existência e funcionamento, ou quanto ao encerramento de suas atividades pela administração educacional" (RUIZ; GIL, 2011, p. 142).

Também não é possível deixar de considerar a educação a partir das condições, situações e circunstâncias nas quais os processos de ensinagem e aprendizagem acontecem, bem como não podemos apartar o meio, a escola e a educação para as comunidades rurais das totalidades maiores, ou seja, da sociedade espanhola, da sociedade europeia, da sociedade mundial e, portanto, do sistema capitalista mundializado. $O$ rural não pode mais ser dissociado do mundo globalizado e de suas tecnologias de produção, informação e comunicação, pois em concretude está conectado diretamente com as transformações produzidas pelo desenvolvimento técnico e científico movimentado e imbricado ao sistema econômico capitalista.

O universo rural, a educação rural, a escola rural e tudo o que representam, no conjunto de valores da atual era digital, exige um novo olhar do universo urbano e da sociedade mundial em si, uma vez que tem sido redefinido, reorganizado, reordenado e adequado às exigências e determinações da globalização econômica, que traduz uma nova ruralidade, caracterizada pela intensificação do acesso e utilização das inovações tecnológicas em permanente transformação.

A inserção do meio rural e da escola rural na sociedade globalizada lhe possibilita, por meio do acesso à informação e comunicação, sair do isolamento característico dos séculos passados, conhecer outras culturas, outros costumes. Assim como as populações urbanas têm maior acesso e conhecimento das verdadeiras realidades vivenciadas pelas diferentes comunidades rurais não apenas da Espanha, do Brasil, da Europa, ou da América, mas de todo o mundo, o que resulta na aproximação das condições de vida disponibilizadas tanto no meio urbano quanto no meio rural. Obviamente, não podemos deixar de considerar as diferenças entre os estilos de vida imanentes aos distintos grupos sociais urbanos e rurais, que abrigam subculturas localizadas em tempos e espaços específicos, portanto, as diferenças entre eles fazem com que o cenário geral seja certamente desigual.

Contudo, várias diferenças culturais entre o rural e o urbano deixam de existir. $\mathrm{O}$ significado dessa nova realidade e o que a tradição concebeu para edificar as comunidades rurais configuram importantes aspectos para análise do campo educacional, visto que "é impossível visualizar vantagens e inconvenientes das mudanças para as pessoas e para as sociedades rurais" (JIMÉNEZ, 2009, p. 1). Estamos, em definitivo, "assistindo ao surgimento de uma nova sociedade rural que, sem esquecer o desenvolvimento agrário é projetada para uma maior diversificação econômica dentro das novas oportunidades oferecidas pelos setores secundário e terciário" (JIMÉNEZ, 2009, p. 2). Essa nova ruralidade é constituída por diversas categorias que, de acordo com Márquez (2002) citada por Jiménez (2009, p. 3-4), podem ser assim especificadas: 
1) Política: as comunidades rurais devem atuar como parte constituinte da vida pública por meio do exercício da democracia participativa e inovadora, com vistas a alcançar uma qualidade de vida para o desenvolvimento integral da pessoa humana e dos recursos à sua disponibilidade; 2) Institucional: é preciso prevalecer o estado de direito com autonomia para a gestão territorial; 3) Econômica: as comunidades rurais devem ser regidas por princípios democráticos econômicos que impõem ao mercado fortes reponsabilidades sociais; 4) Cultural: a nova ruralidade está assentada no reconhecimento e valorização de suas diversidades culturais; 5) Ambiental: as comunidades rurais precisam ajustarem-se aos princípios de desenvolvimento sustentável e incorporar a riqueza ambiental de modo a propiciar a melhoria da qualidade de vida; 6) Territorial: as comunidades rurais devem representar a associação dos projetos locais e regionais com autonomia plena para a realização de suas proposições, o que supõe uma articulação territorial planejada.

É na direção do resgate e preservação da cultura rural que inúmeras iniciativas tanto de movimentos sociais quanto do próprio Estado ganharam expressão em terras espanholas, assim como se processou no Brasil, com destaque ao protagonismo desempenhado pelo Movimento dos Trabalhadores Rurais Sem Terra (MST), que além da luta pela terra e em defesa dos costumes, das tradições e da diversidade cultural que caracterizam as populações rurais brasileiras, também se ocupou com grande afinco à luta por uma educação de qualidade para as populações acampadas e assentadas nas mais diversas localidades do território brasileiro, por meio da realização do I Encontro Nacional de Educadores na Reforma Agrária (1997), I Conferência Nacional por uma Educação Básica do Campo (1998), I Seminário do Programa Nacional de Educação na Reforma Agrária (2003), I Conferência Nacional por uma Educação Básica do Campo: por uma Política Pública de Educação do Campo (2004) .

Jiménez (2009, p. 4) ressalta a importância da atuação dos movimentos sociais na Espanha em busca da revalorização do meio e da cultura rural junto ao Estado e à sociedade, sob o argumento de que constitui fato e reafirma as manifestações contrárias à crise ambiental que tem caracterizado a realidade urbano-industrial atual, "contra a qual o rural é proposto como forma de vida vinculada à natureza e desejável por sua qualidade como âmbito do desenvolvimento de atividades de trabalho, de lazer, de turismo etc".

\section{Educação rural espanhola à luz do século XXI}

Há de se considerar, segundo Jiménez (2009), que a imagem do rural vinculado ao passado, ao antigo, ao atraso vem sendo superada gradativa e relativamente, considerando as transformações de que o meio rural estritamente tradicional, homogêneo e restrito à localidade não cabe no mundo globalizado, não fica e não está isolado, pois a sociedade da informação não permite a sua invisibilidade. De acordo com as análises de Hernández Díaz (2000, p. 127), o que deve ser levado em conta não pode se restringir ao:

[...] encanto dos valores da natureza, dos sistemas gerenciáveis de produção e transformação econômica, de criação e transmissão de valores e modelos culturais, escolares e religiosos da sociedade rural tradicional que sobreviveu à história da Espanha ao longo dos séculos; escapa de maneira definitiva a um modelo de sociedade, de escola e de Espanha do passado, na medida em que emergem com 
vigor frenético e incontrolável outros tipos de cultura, de mecanismos de produção, de transmissão do conhecimento e também de escola.

A escola rural, a escola de aldeia, a escola estabelecida no meio rural, unitária, mista ou agrupada, assim como a própria sociedade rural tradicional, que permaneceu historicamente esquecida e desvalorizada no passado, enfrenta na atualidade transformações de modelo e orientação, inauguradas a partir das reformas educacionais do último quartel do século XX. A Espanha do século XXI não mais se assenta numa estrutura estritamente social rural, não é orientada por uma mentalidade predominantemente campesina, assim como não é o setor primário o mais importante no conjunto do sistema produtivo do país, o universo rural espanhol não tem, em situação alguma, o mesmo significado que tinha há quarenta, cinquenta ou cem anos atrás. Portanto, todos os aspectos, elementos, questões, necessidades e carências que constituem a denominada escola rural não podem ser considerados isoladamente e muito menos desvinculados da sociedade globalizada (HERNÁNDEZ DÍAZ, 2010).

A efetivação da educação rural no contexto espanhol atual precisa considerar que o reconhecimento do direito à igualdade de condições e a uma educação de qualidade são imprescindíveis para o desenvolvimento das populações rurais. O Estado precisa assumir o compromisso com essas populações para implementar políticas afirmativas com vistas à redução das desigualdades econômicas e sociais, mediante a disponibilização de recursos econômico-financeiros, físicos, materiais e humanos efetivos para a oferta, manutenção e desenvolvimento de uma educação que contemple as necessidades de formação para a inserção e permanência das populações que habitam no meio rural ao mercado de trabalho no meio rural (ÁLVAREZ; SÁNCHEZ; HINOJO LUCENA, 2013).

Hernández Díaz (2000) reitera os nossos apontamentos ao inferir que uma das principais transformações ocorridas no sistema educacional espanhol, nos últimos anos do século XX, decorreu diretamente do processo de reordenação do sistema econômico capitalista, da mundialização da economia, da sociedade capitalista de predominância industrial e urbana. Nesse contexto, tanto a educação quanto a escola não ficam alheias a tais processos econômicos e sociais, "que jamais podem ser explicados linearmente no tempo e na forma, pois levam à substituição majoritária de uma estrutura educacional rural por outra de domínio urbano" (HERNÁNDEZ DÍAZ, 2000, p. 114-115).

A sociedade espanhola está completamente envolvida num modelo de organização da vida e do trabalho no meio rural, que não existe mais nenhuma possibilidade de retorno ao passado tradicional, em que pese a organização e ação tecnocrática no capitalismo mundializado, "de produção agrária e intensa mercantilização jamais vista na história dos espanhóis", complementa Hernández Díaz (2000, p. 127). Entretanto, nesse processo político controverso sobre a educação e a escola para as populações que habitam no meio rural:

[...] que alcançou seu ápice nos anos finais da década de 1980 com a intervenção da opinião pública, dos Movimentos de Renovação Pedagógica, do Movimento Cooperativo de Escola Popular, dos sindicatos da educação, de todos os grupos políticos, das administrações autônomas com ou sem competências educacionais transferidas, de muitas corporações municipais e cidadãos em particular, debates foram alimentados e um amplo movimento em defesa da escola rural foi organizado nas mais diversas partes da Espanha, o que conduziu a algumas soluções técnicas e políticas para a questão e a uma melhor e maior consideração pedagógica para o que 
significa, ou deve representar a escola no meio rural (HERNÁNDEZ DÍAZ, 2000, p. 131).

Hernández Díaz (2000) concorda com os postulados de Tomás (2004) ao inferir que, boa parte da melhoria das condições da educação para as comunidades rurais nos dias atuais, decorre diretamente das principais propostas do movimento em defesa da escola rural, como, por exemplo, a criação dos CRAs e sua incorporação à Lei Orgânica de Organização Geral do Sistema Educacional (1990) ${ }^{\mathrm{vi}}$. Diferentes medidas estão direta ou indiretamente associadas a programas compensatórios de educação, sistemas de instalação de centros e salas de aula para o ensino secundário obrigatório, edificação de novas escolas e adequação das instalações já existentes nos povoamentos com maior capacidade atrativa e abordagem tímida do processo de formação profissional orientados para as atividades produtivas rurais (HERNÁNDEZ DÍAZ, 2000).

Não é possível negar que significativos avanços se materializaram no sistema educacional espanhol, substancial salto qualitativo foi concretizado, especialmente, no que diz respeito à educação rural, à escola para as comunidades do meio rural, aos centros educacionais nas áreas rurais, mas ainda são insuficientes, pois há muito a avançar, considerando que inúmeras reivindicações da sociedade civil, das organizações e associações de classe, dos movimentos em defesa das escolas rurais, dos pesquisadores que se debruçam sobre a temática e dos cidadãos em sentido lato não foram atendidas. Portanto, é necessária a atenção permanente à manutenção e melhoria das condições de existência da escola rural, com ensino de boa qualidade, que a considere em suas particularidades e necessidades, bem como na impossibilidade plena de seu apartamento do meio urbano, da sociedade espanhola, da sociedade capitalista globalizada.

As fundamentações teóricas contidas nos escritos de Márquez (2002), Feu Gelis (2004), Jiménez (2009), Álvarez, Sánchez e Hinojo Lucena (2013), renovam as considerações de Hernández Díaz (2000), de que tanto a educação rural como a escola rural na Espanha, historicamente, não receberam a devida atenção, preocupação, tratamento específico e diferenciado suficientes para atender aos diferentes níveis de ensino, às necessidades, carências e particularidades nas localidades em que se encontram instaladas ${ }^{\mathrm{vii}}$. A não preocupação das autoridades políticas espanholas com a educação e a escola rural, que se estendeu até o último quartel do século XX, produziu substancial deterioração do serviço público educacional para as comunidades rurais e, para além de tais limites, desrespeitou sistematicamente os direitos educacionais de crianças, adolescentes, jovens e adultos; desrespeitou o cidadão espanhol (HERNÁNDEZ DÍAZ, 2000).

$\mathrm{Na}$ atualidade, podemos apontar com convicção, a existência de dois tipos de escolas disponibilizadas para as comunidades do meio rural na Espanha: de um lado estão as agrupadas e constituem jurídica e administrativamente uma espécie de centro unificado de educação, mas na prática, reúne várias escolas de diferentes localidades que têm atribuída uma mesma denominação, um mesmo projeto pedagógico, um mesmo conselho escolar, quadro de professores e equipe de direção; por outro lado, estão os centros isolados que devido às distâncias territoriais encontram-se impossibilitados de constituir um centro rural agrupado (HEREDERO; GONZÁLEZ; NOZU, 2014). 
Pensar e refletir sobre o futuro da educação para as populações que residem no meio rural constitui uma questão extremamente dinâmica, complexa e relativamente restrita às políticas públicas de educação imbricadas às políticas sociais e econômicas mais amplas que devem e precisam ser implementadas em tais contextos. Não é possível apontar o que pode acontecer com a oferta da educação para as comunidades rurais sem antes considerar a sua vinculação direta com os âmbitos produtivo, demográfico, territorial, relacional, ambiental e cultural.

É preciso distinguir a educação rural no contexto das inumeráveis interações e relações que movimentam os diferentes processos na sociedade capitalista em sua totalidade e que possa contemplar o desenvolvimento pleno, equilibrado e sustentável tanto do espaço quanto das populações que compõem o meio rural, tendo em vista a melhoria da qualidade de vida e da promoção da igualdade de oportunidades para todos (HEREDERO; GONZÁLEZ; NOZU, 2014).

Ruiz e Gil (2011) defendem que não podemos pensar e/ou refletir sobre um futuro para o meio rural e inexoravelmente para a educação rural sem levar em conta o desenvolvimento global e local do meio. "Nesse desenvolvimento global, a formação escolar constitui um eixo fundamental para a transformação social do ambiente", isto é, um recurso imprescindível "para abrir novas perspectivas de emprego para poder sair da cultura assistencialista em que estão por vezes imersos, para melhorar a qualificação de trabalhadores, permitir o acesso a outros postos de trabalho", bem como para suprimir "a falta de iniciativas sociais" (RUIZ; GIL, 2011, p. 144).

Acreditamos ser pertinente ressaltar que a nossa busca por algumas definições conceituais sobre a educação rural construídas pelos intelectuais analisados no presente estudo, sempre procurou considerar as dificuldades e as complexidades que envolvem e caracterizam tanto a escola, a educação e, sobretudo, a terminologia rural, uma vez que conserva em si uma visão intricada e multidimensional que abrange inúmeros elementos e considerações, o que indubitavelmente, não permite apresentar apenas uma "definição universal e permanentemente válida de [educação rural], sem ter uma visão de conjunto para não desembocar numa dicotomia simplista, pois [rural e urbano] estão em permanente transformação" (BERLANGA QUINTERO, 2003, p. 27).

Não devemos e não podemos nos limitar a considerar apenas as atividades produtivas agrícolas ou não agrícolas como parâmetros para diferenciar se um determinado meio é rural ou urbano, pois o aumento das atividades não agrícolas no meio rural tem constituído indiscutível realidade desde a década de 1990, "tanto nos países desenvolvidos, como é o caso dos Estados Unidos da América (EUA), quanto na América Latina de modo geral, e no Brasil em particular" (SILVA, 2002, p. 61). Em nossa apreensão, o meio rural pode e deve ser contemplado tanto como produtor de cultura quanto como produto, tanto como criativo quanto como espaço para a construção do novo, portanto:

[...] não deve ser reduzido a espaço de produção econômica, mas reconhecido e considerado enquanto e como espaço de produção econômica, não como espaço do velho, do passado, do antigo e da não cultura, mas como parte componente de um universo mais amplo, associado e imbricado ao espaço urbano, às periferias, aos 
rios, aos mares, ao mundo e à sociedade em toda a sua extensão e heterogeneidade (SANTOS; BEZERRA NETO, 2017a, p. 455).

Como podemos observar, são diversas as indicações conceituais sobre o rural e sobre a educação rural na atualidade que, segundo Álvarez (2000), chegam a colocar em dúvida a própria existência da ruralidade ante à urbanidade no contexto socioeconômico e cultural do século XXI. Encontramos uma educação em que a classificação do rural pode até mesmo constituir inconveniência ao invés de solução para os seus problemas e necessidades. Entretanto, não devemos nos ater a tais inconveniências terminológicas, precisamos nos encaminhar para a "compreensão da educação a partir das circunstâncias particulares em que sua tarefa de ensino é desenvolvida; circunstâncias que não podem e não devem ser dissociadas do contexto em que ocorrem: o contexto rural"' (RUIZ; GIL, 2011, p. 142-143).

Fernandes (2002), por sua vez, argumenta que a educação constitui recurso fundamental para o desenvolvimento humano e aponta para uma nova trajetória daqueles que acreditam que os meios rural e urbano se complementam e:

[...] precisam ser compreendidos como espaços geográficos singulares e plurais, autônomos e interativos, com suas identidades culturais e modos de organização diferenciados, que não podem ser pensados como relação de dependência eterna ou pela visão 'urbanoide' e totalitária, que prevê a intensificação da urbanização como modelo de país moderno. A modernidade é ampla e inclui a todos, do campo e da cidade (FERNANDES, 2002, p. 62-63).

A função social e formativa desempenhada pela educação e pela escola no meio rural é singular, exprimem Ruiz e Gil (2011), ou seja, a formação escolar/educacional desenvolvida pela educação contribui para:

1) dar voz às culturas rurais silenciadas e para afirmar seu valor e potencialidade no contexto da mundialização; 2) defender e assegurar a identidade coletiva e cultural rural, bem como para conservar o patrimônio natural e histórico; 3) a constituição de centro de atividade educativa, cultural, social, de relação e de participação; 4) um modelo alternativo ao desenvolvimento de estratégias de resistência e para fazer frente à organização hegemônica dos centros educacionais e a um modelo particular de cultura imposta e legitimada desde o meio urbano por meio do sistema educacional; 5) um mecanismo para suprir as necessidades de formação escolar da população em geral e que garanta o princípio de igualdade de oportunidades; 6) uma contribuição na reconstrução do conceito de ruralidade como projeto de vida autônomo, integral e que contemple as próprias necessidades e valores (CARIDE, 1998 apud RUIZ; GIL, 2011, p. 143-144).

Na concepção de Tomás (2004, p. 13), conforme apontamos anteriormente, a educação rural pode ser definida como aquela que tem a sua sustentação indissociável tanto do meio quanto da cultura rurais, com uma estrutura organizacional didático-pedagógica assentada no atendimento à "heterogeneidade e multinivelaridade de grupos de alunos com idades, capacidades, competências e níveis de escolarização distintas, adaptados às características e necessidades inerentes ao contexto em que se insere" sem, no entanto, se apartar da totalidade, ou seja, da sociedade em si. 


\section{Considerações finais}

Imbricadas às transformações estruturais do sistema econômico capitalista do final do século XX, o pensamento, a identidade e atividades sociais e culturais das populações rurais também se modificaram, se desenvolveram, evoluíram e possibilitaram a criação de novos elementos para a organização educacional e educativa no interior das escolas, como novos métodos e instrumentos pedagógicos, materiais de trabalho mais apropriados para a satisfação das necessidades em nível local intimamente relacionado ao contexto europeu e, particularmente, à região sul do continente, em que a escola possui espaços e características reconhecidamente particularizadas.

$\mathrm{Na}$ Espanha do século XXI existem, insistem e persistem diferentes modelos institucionais de educação com formas, dinâmicas, ritmos e peculiaridades distintas como os centros escolares rurais, os individuais completos, os individuais incompletos e os centros rurais agrupados. As reformas realizadas, nas últimas décadas, nas práticas exprimem a busca pela permanente reavaliação pedagógica da educação no meio rural e da escola rural por seu valor e importância para as comunidades locais, mesmo a escola unitária isolada e multisseriada das fazendas, pequenos povoados e aldeias, "além de outras repercussões de ordem social, territorial, demográfica ou de manutenção da população no meio rural por razões políticas e econômicas" (HERNÁNDEZ DÍAZ, 2000, p. 134).

A educação rural espanhola precisa considerar as circunstâncias e condições em que acontecem os processos de ensino e de aprendizagem. O universo, a educação e a instituição escolar precisam ser reconhecidas como partes constituintes da sociedade espanhola, da sociedade europeia, da sociedade mundial e, portanto, do sistema capitalista em tempos de globalização. Portanto, o meio rural não pode ser dissociado da mundialização econômica com suas vantagens e desvantagens, em que pese as suas tecnologias de produção, de informação e de comunicação, pois é indissociável do conjunto de transformações produzidas pelo desenvolvimento técnico e científico movimentado pelo sistema capitalista de produção.

$\mathrm{Na}$ direção das constatações e proposições dos especialistas espanhóis convergem as argumentações dos especialistas brasileiros ao apontarem que: a educação para as populações rurais brasileiras pode ser entendida por sua vinculação às questões inerentes às singularidades, às particularidades, às realidades locais, ancorada na temporalidade, "na memória coletiva que sinaliza futuros, na rede de ciência e tecnologia disponível na atualidade e nos movimentos sociais em defesa de projetos que associem as soluções exigidas por essas questões à qualidade social da vida coletiva no país”, mas jamais, apartada da sociedade capitalista em permanente globalização (BRASIL, 2002).

Independente das realidades e dos territórios, a educação rural precisa ser apreendida no conjunto das imensuráveis interações e relações que expressam a dinamicidade e complexidade das oposições e contrárias características da sociedade capitalista, com vistas a alcançar o máximo desenvolvimento humano, social, econômico, político, cultural e ambiental possível, tanto do meio rural como do rurícola, bem como assegurar a melhoria da qualidade de vida e da promoção da igualdade de oportunidades sem distinção de classes, ou melhor, sem privilegiar uma classe em detrimento da outra. Para tanto, é indispensável a 
atenção permanente para que a melhoria das condições de existência da educação e da escola rural com ensino de boa qualidade se materialize efetivamente; que o universo rural seja considerado inseparável do universo urbano, submetidos às consequências das movimentações e transformações do sistema econômico e, portanto, espaços constituintes da mesma sociedade.

Reiteramos que os processos de mudanças na contemporaneidade têm caminhado de forma simultânea nas mais diversas regiões e províncias, tanto da heterogênea sociedade rural espanhola, quanto das realidades vividas no interior do território brasileiro, onde podemos encontrar concepções educacionais, educativas e escolares diferenciadas e segmentadas, assim como diversas práticas culturais rurais, que traduzem as suas pluralidades e riquezas culturais e pedagógicas. Cabe aqui ressaltar - tomando em empréstimo as palavras de Ruiz e Gil (2011, p. 144) -, que a educação, a escola, a formação escolar no meio rural se manterão vivas enquanto existir a necessidade de meios para a subsistência, pois "as produções agrícola e pecuária continuam constituindo os alicerces de fundamentação para o desenvolvimento socioeconômico e satisfação das necessidades alimentares da população, bem como para o equilíbrio territorial, valorização e revitalização das áreas rurais" e manutenção da sociedade global.

\section{Referências}

ÁLVAREZ, Eudaldo Corchón. La escuela rural: pasado, presente y perspectivas de futuro. Barcelona: Oikos-Tau, 2000.

ÁLVAREZ, Eudaldo Corchón; SÁNCHEZ, Francisco Raso; HINOJO LUCENA, María Angustias. Análisis histórico-legislativo de la organización de la escuela rural española en el período 1857-2012. Enseñanza e Teaching. Salamanca, v. 31, n. 1, p. 147-179, 2013.

BERLANGA QUINTERO, Salvador. Educación en el medio rural: análisis, perspectivas y propuestas. Zaragoza: Mira Editores, 2003.

BEZERRA NETO, Luiz; SANTOS, Flávio Reis. Escolas estaduais em assentamentos e escolas urbanas: uma comparação a partir do SARESP. In: BASSO, Jaqueline Daniela; SANTOS NETO, José Leite; BEZERRA, Maria Cristina dos Santos (org.). Pedagogia histórico-crítica e educação no campo: história, desafios e perspectivas atuais. São Carlos: Pedro \& João Editores e Navegando, 2016. p. 243-271.

BRASIL. Decreto n. 7.352, de 4 de novembro de 2010. Dispõe sobre a política de educação do campo e o Programa Nacional de Educação na Reforma Agrária - PRONERA. Diário Oficial da União, Brasília, DF, 5 nov. 2010.

BRASIL. Resolução CNE/CEB n. 1, de 3 de abril de 2002. Institui Diretrizes Operacionais para a Educação Básica nas Escolas do Campo. Diário Oficial da União, Brasília, DF, 9 abr. 2002. 
ESPAÑA. Ley 14/1970, de 4 de agosto de 1970, General de Educación y Financiamiento de la Reforma Educativa. Boletín Oficial del Estado (BOE), n. 187. Madrid, 6 ago. 1970.

ESPAÑA. Real Decreto n. 1.174, de 27 de abril de 1983, sobre Educación Compensatoria. Boletín Oficial del Estado (BOE), n. 112. Madrid, 11 mayo 1983.

ESPAÑA. Real Decreto n. 2.731, de 24 de diciembre de 1986, sobre Constitución de Colegios Rurales Agrupados de Educación General Básica. Boletín Oficial del Estado (BOE). Madrid, 9 enero 1987.

FAGUNDES, José; MARTINI, Adair Cesar. Políticas educacionais: da escola multisseriada à escola nucleada. Olhar de Professor, Ponta Grossa, v. 6, n. 1, p. 99-118, 2003.

FERNANDES, Bernardo Mançano. Diretrizes de uma caminhada. In: KOLLING, Edgar Jorge; CERIOLI, Paulo Ricardo; CALDART, Roseli Salete (org.). Educação do campo: identidade e políticas públicas. Brasília, DF: Articulação Nacional por uma Educação do Campo, 2002. p. 61-70.

FEU GELIS, Jordi. La escuela rural en España: apuntes sobre las potencialidades pedagógicas, relacionales y humanas de la misma. Revista Digital eRural, Educación, Cultura y Desarrollo Rural, año 2, n. 3, p. 1-13, junio 2004.

HAGE, Salomão Mufarrej; REIS, Maria Izabel Alves. Tempo, espaço e conhecimento nas escolas rurais (multi)seriadas e transgressão ao modelo seriado de ensino. Em Aberto, Brasília, v. 31, n. 101, p. 77-91, jan./abr. 2018.

HEREDERO, Eladio Sebastián; GONZÁLEZ, Claudia Inés Collado; NOZU, Washington Cesar Shoiti. Los colegios rurales agrupados en España: analisis del funcionamiento y organización de la escuela rural española a partir de un estudio de casos. Educação e Fronteiras On-Line, Dourados, v. 4, n. 12, p. 142-153, set./dez. 2014.

HERNÁNDEZ DÍAZ, José María. La escuela rural en la España del siglo XX. Revista de Educación. Espanha, n. Extra 1, p. 113-136, 2000.

HINOJO, Francisco Javier; RASO, Francisco; HINOJO, María Angustias. Análisis de la organización de la escuela rural en Andalucía: problemática y propuestas para un desarrollo de calidad. Revista Iberoamericana sobre Calidad, Eficacia y Cambio en Educación, Madrid, v. 8, n. 2, p. 79-105, 2010.

JANATA, Natacha Eugênia; ANHAIA, Edson Marcos. Escolas/classes multisseriadas do campo: reflexões para a formação docente. Educação \& Realidade, Porto Alegre, v. 40, n. 3, p. 685-704, jul./set. 2015. https://doi.org/10.1590/2175-623645783.

JIMÉNEZ, Antonio Bustos. Valoraciones del profesorado de escuela rural sobre el entorno presente. Revista Iberoamericana de Educación, Madrid, v. 48, n. 6, p. 1-11, 2009.

LEITE, Sérgio Celani. Escola rural: urbanização e políticas educacionais. 2. ed. São Paulo: Cortez, 2002. 
LOPES, Wiama de Jesus Freitas; BEZERRA NETO, Luiz. A multisseriação frente à profissionalidade docente na educação do campo. Revista HISTEDBR On-line, Campinas, v. 13, n. 50, p. 77-89, maio 2013. https://doi.org/10.20396/rho.v13i50.8640295.

LUNA, Rogeli Santamaria. Un poco de historia de la escuela rural en España. Escuelarural, España, 2010. Disponível em:

http://escuelarural.net/IMG/pdf/UN_POCO_DE_HISTORIA_DE_LA_ESCUELA_RURAL EN_ESPANA.pdf. Acesso em: 16 jan. 2018.

MÁRQUEZ, Dominga (coord.). Nuevos horizontes en el desarrollo rural. Madrid, Akal, 2002.

MOURA, Terciana Vidal; SANTOS, Fábio Josué Souza. A pedagogia das classes multisseriadas: uma perspectiva contra-hegemônica às políticas de regulação do trabalho docente. Debates em Educação, Maceió, v. 4, n. 7, p. 65-86, 2012.

https://doi.org/10.28998/2175-6600.2012v4n7p65

RUIZ, Maria del Pilar Sepúlveda; GIL, Monsalud Gallardo. La escuela rural en la sociedade globalizada: nuevos caminos para uma realidad silenciada. Revista del Currículum y Formación del Profesorado, v. 15, n. 2, p. 141-153, 2011.

SÁNCHEZ, Jesús Jiménez. La escuela unitaria. Barcelona: Laia, 1983.

SANTOS, Flávio Reis; BEZERRA NETO, Luiz. Movimento sociais e políticas públicas de educação para as populações que habitam no meio rural. Impulso, Piracicaba, v. 27, n. 70, p. 17-32, set./dez. 2017b. https://doi.org/10.15600/2236-9767/impulso.v27n70p17-32.

SANTOS, Flávio Reis; BEZERRA NETO, Luiz. Políticas públicas para a educação rural no Brasil: da omissão à regulamentação do Programa Nacional de Educação na Reforma Agrária. Revista HISTEDBR On-line, Campinas, v. 15, n. 66, p. 178-195, dez. 2015. https://doi.org/10.20396/rho.v15i66.8643709.

SANTOS, Flávio Reis; BEZERRA NETO, Luiz. Práxis educativa para as populações campesinas brasileiras: do ruralismo pedagógico ao materialismo histórico-dialético. Acta Scientiarum Education, Maringá, v. 39, n. 4, p. 453-467, Oct./Dec. 2017a. https://doi.org/10.4025/actascieduc.v39i4.31676.

SILVA, José Graziano. O novo rural brasileiro. 2 ed. Campinas: IE/Unicamp, 2002.

TOMÁS, Roser Boix (coord.). La escuela rural: funcionamiento y necesidades. Madrid: Ciss Praxis, 2004.

WANDERLEY, Maria de Nazareth Baudel. A emergência de uma nova ruralidade nas sociedades modernas avançadas: o "rural" como espaço singular e ator coletivo. Estudos Sociedade e Agricultura, v. 8, n. 2, p. 87-145, out. 2000.

\section{Notas}

${ }^{\text {i }}$ Ley General de Educación y Financiamiento de la Reforma Educativa n. 14 (ESPAÑA, 1970). 
ii Sob o pressuposto de melhorar a qualidade do sistema educacional, o governo espanhol promoveu a criação de colégios nacionais com grupos de 30 alunos na mesma faixa etária e, em contrapartida, o encerramento das atividades educativas em escolas com baixa demanda. Muitas escolas das aldeias e pequenos povoados tiveram as suas portas fechadas e os alunos foram agrupados em unidades centrais nas cidades (LUNA, 2010).

iii Consultar: Capítulo 3. "Tecnocracia e Utilitarismo" e Capítulo 4. "Liberalismo e Tecnocracia" (SANTOS, 2015). SANTOS, Flávio Reis. Capitalismo, tecnocracia e educação: da utopia social saintsimoniana à economia (neo)liberal friedmaniana. Jundiaí: Paco Editorial, 2015.

iv Província espanhola da Comunidade de Leão e Castela. As muralhas que circundam a cidade foram declaradas Patrimônio Mundial da Humanidade pela Organização das Nações Unidas para a Educação, a Ciência e a Cultura (UNESCO).

v "A primeira conquista decorrente da trajetória de mobilização e lutas empreendidas pelos movimentos sociais pode ser expressa pelo Programa Nacional de Educação na Reforma Agrária (PRONERA), pois representa marco substancial na busca do direito à educação para os sujeitos que vivem no meio rural e, por desempenhar função de grande importância para contribuir com a diminuição das desigualdades escolares, sociais e econômicas brasileiras, na medida em que procurou viabilizar a implantação de políticas públicas para assegurar o acesso à educação básica e superior, à formação profissional, à formação de educadores e à defesa da escola pública em áreas rurais" (SANTOS; BEZERRA NETO, 2017b, p. 20).

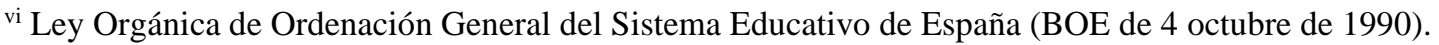

vii Ocorrência também constatada nos contextos históricos que marcaram e demarcaram a educação para as populações rurais no Brasil e que levaram a intelectualidade orgânica do Movimento dos Trabalhadores Rurais Sem Terra a definir a partir da educação as populações a que se destina, a saber: os agricultores familiares, os extrativistas, os pescadores artesanais, os ribeirinhos, os assentados e acampados da reforma agrária, os trabalhadores assalariados rurais, os quilombolas, os caiçaras, os povos da floresta, os caboclos e outros que produzam suas condições materiais de existência a partir do trabalho no meio rural (BRASIL, 2010).

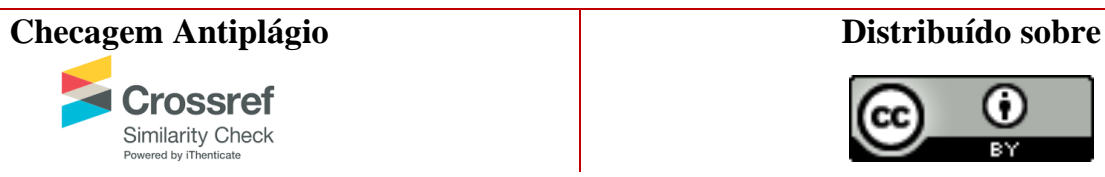

